\title{
Testosterone-Dependent miR-26a-5p and let-7g-5p Act as Signaling Mediators to Regulate Sperm Apoptosis via Targeting PTEN and PMAIP1
}

\author{
Jideng Ma ${ }^{1,+}{ }^{,}$Yu Fan ${ }^{1,+}$, Jinwei Zhang ${ }^{1,+}$, Siyuan Feng ${ }^{1}$, Zihui Hu ${ }^{1}$, Wanling Qiu ${ }^{1}$, \\ Keren Long ${ }^{1}$, Long Jin ${ }^{1}$, Qianzi Tang ${ }^{1}$, Xun Wang ${ }^{1}$, Qi Zhou ${ }^{2}$, Yiren Gu ${ }^{3}$, Weihang Xiao ${ }^{1}$, \\ Lingyan Liu ${ }^{1}$, Xuewei $\mathrm{Li}^{1}$ and Mingzhou $\mathrm{Li}^{1}{ }^{1, *}$ \\ 1 Farm Animal Genetic Resource Exploration and Innovation Key Laboratory of Sichuan Province, \\ Sichuan Agricultural University, Chengdu 611130, China; jideng.ma@sicau.edu.cn (J.M.); \\ fanxiao123yu@126.com (Y.F.); Jinweizhang50@163.com (J.Z.); siyuanfeng_bioinfo@163.com (S.F.); \\ huzihui2018@163.com (Z.H.); qiuwanling2016@163.com (W.Q.); longkeren@163.com (K.L.); \\ longjin8806@163.com (L.J.); wupie@163.com (Q.T.); xun_wang007@163.com (X.W.); \\ weihang.xiao@sicau.edu.cn (W.X.); lingyan.liu@sicau.edu.cn (L.L.); xuewei.li@sicau.edu.cn (X.L.) \\ 2 Chengdu Polytechnic, Chengdu 610041, China; Qizhou0205@126.com \\ 3 Animal Breeding and Genetics Key Laboratory of Sichuan Province, Pig Science Institute, Sichuan Animal \\ Science Academy, Chengdu 610066, China; guyiren1128@163.com \\ * Correspondence: mingzhou.li@sicau.edu.cn; Tel.: +86-28-8629-0962 \\ + These authors contributed equally to this work.
}

Received: 20 March 2018; Accepted: 13 April 2018; Published: 18 April 2018

\begin{abstract}
Recent evidence suggests that testosterone deficiency can dramatically decrease the quality of sperm. MicroRNAs (miRNAs) are conserved mediators of post-transcriptional gene regulation in eukaryotes. However, the systemic regulation and function of miRNAs in sperm quality decline induced by testosterone deficiency has not been investigated. Here, we found that the sperm apoptosis was significantly enhanced and the sperm motility was dramatically decreased in hemicastrated pigs. We then used small RNA sequencing to detect miRNA profiles of sperm from pigs with prepubertal hemicastration (HC) and compared them with control libraries. We identified 16 differentially expressed (DE) miRNAs between the sperm of prepubertal HC and control (CT) pigs. Functional enrichment analysis indicated that the target genes of these DE miRNAs were mainly enriched in apoptosis-related pathways including the p53, mitogen-activated protein kinase (MAPK), and mammalian target of rapamycin (mTOR) pathways. Furthermore, gain- and loss-of-function analyses demonstrated potential anti-apoptotic effects of the DE miRNAs miR-26a-5p and let-7g-5p on sperm cells. The luciferase reporter assay confirmed that PTEN and PMAIP1 are targets of miR-26a-5p and let-7g-5p, respectively. Spearman's correlation analysis revealed significantly positive correlations between the sperm and its corresponding seminal plasma exosomes regarding the miRNA expression levels. In conclusion, testosterone deficiency-induced changes in the miRNA components of seminal plasma exosomes secreted by the genital tract may partially elucidate sperm miRNAome alterations, which are further responsible for the decline of sperm motility.
\end{abstract}

Keywords: testosterone deficiency; sperm motility; apoptosis; miRNA; exosome

\section{Introduction}

Mammalian testes have two main functions, spermatogenesis and androgen secretion. Spermatogenesis occurs in the seminiferous tubules of the postpubertal testis [1], while androgen formation and secretion take place in the interstitium of Leydig cells [2]. Testosterone is the primary 
and best recognized androgenic steroid hormone, which has multiple physiological effects in various target organs and plays a key role in testicular development and spermatogenesis [3]. Testosterone deficiency causes faulty development of reproductive organs and abnormal spermatogenesis and eventually leads to male reproductive disorders that are clinically termed hypogonadism [4]. Previous studies indicated that androgen receptor (AR) knockout, whether in Sertoli cells (S-AR ${ }^{-/ y}$ ) [5] or total AR knockout $\left(\mathrm{T}-\mathrm{AR}^{-/ \mathrm{y}}\right)$ in mice [6], induces spermatogenesis arrest at the diplotene premeiotic stage, causing oligospermia and infertility. As an indispensable clinical testosterone deficiency model [7], prepubertal hemicastration can dramatically induce hypertrophy of the remaining testis through the rapid proliferation of Leydig cells and Sertoli cells [8,9]; moreover, it can decrease sperm counts and semen volume in male beagles [10], but enhances daily sperm production in the remaining testis of aged rats [11]. These results highlight the important role of testosterone in spermatogenesis and semen quality; however, the molecular mechanisms involved still remain poorly understood.

MicroRNAs (miRNAs) are non-coding RNAs $\sim 22$ nucleotides long that are derived from stem-loop precursors (pre-miRNAs) and regulate eukaryotic gene expression at the post-transcriptional level $[12,13]$. During the past decade, miRNAs were shown to be involved in various biological processes including development [14], cell growth [15], and differentiation [16]. Semen is a complex viscous fluid composed of spermatozoa and seminal plasma from seminiferous tubules, the epididymis, and accessory glands (including seminal vesicles, the prostate, and bulb urethral glands) [17]. Normozoospermic and asthenozoospermic men have different sperm miRNA expression profiles, suggesting that miRNAs affect sperm quality through several potential target genes [18]. miR-34c is highly expressed in mouse sperm, where it is critical for the first cleavage division [19]. Seminal plasma contains exosomes produced by the epididymis and accessory glands [20] and is characterized by high cholesterol and sphingomyelin content and a complex protein composition in humans, rats [21,22], rams [23], and boars [24]. Recent reports found that seminal exosomes in humans and mice contain small non-coding RNAs (miRNAs and tRNA-derived RNA fragments (tRFs)) with potential regulatory functions that aid fertilization and the intergenerational inheritance of an acquired metabolic disorder [25-27]. Thus, we hypothesized that miRNAs in sperm cells and seminal plasma exosomes play vital regulatory roles in maintaining the normal process of spermatogenesis and are responsible for testosterone deficiency-induced male reproductive disorders.

To test our hypothesis, we systematically and comprehensively compared the miRNA profiles of sperm cells between prepubertally hemicastrated Yorkshire boars (HC) and normal controls (CT). We found that differentially expressed (DE) miRNAs were mainly enriched in pathways involved in cell apoptosis, including the mammalian target of rapamycin (mTOR) and p53 signaling pathways. Furthermore, gain- and loss-of-function analyses and dual luciferase assays demonstrated that endogenous miR-26a-5p and let-7g-5p have potential anti-apoptotic and pro-survival functions in sperm cells through targeting PTEN and PMAIP1 genes. Further comparisons revealed high similarities in miRNA profiles between seminal plasma exosomes and sperm cells, both in HC and CT groups. Our study revealed that miRNAs in sperm cells and seminal plasma exosomes have important functions in male reproduction, suggesting they could be used as potential treatment targets or novel diagnostic markers for male infertility.

\section{Results and Discussion}

\subsection{Establishment of a Testosterone Deficiency Model in Yorkshire Boars}

Previous research has investigated testosterone deficiency by prepubertal hemicastration in mice, rats, beagle dogs, and boars from a physiological perspective, with a particular focus on endocrine levels. To explore the comprehensive effects of testosterone deficiency on the development of the main organs, we carried out hemicastration in prepubertal Yorkshire boars (seven days old) to establish a testosterone deficiency model. At the body maturation stage (10 months old), several phenotypic indexes were assessed in HC $(n=15)$ and CT $(n=15)$ pigs. This revealed no obvious alterations in body 
weight or length, chest circumference, or several organ indexes between HC and CT pigs (Figure 1A-C). However, significant differences were observed with respect to reproduction, including reduced serum testosterone $(1197 \pm 109$ versus $1458 \pm 37 \mathrm{nmol} / \mathrm{L}, p<0.01)$, an increased testis index $(0.24 \pm 0.03$ versus $0.28 \pm 0.03 \%, p<0.01$ ), and an increased size of the remaining testis (length: $16.23 \pm 1.82$ versus $22.36 \pm 2.19 \mathrm{~cm}, p<0.01$; width: $14.13 \pm 1.55$ versus $20.45 \pm 1.97 \mathrm{~cm}, p<0.01)$ in HC compared with CT pigs (Figure 1D-F). Histomorphological analysis showed that the hypertrophy of the remaining testis in hemicastrated pigs was associated with a significantly increased diameter of the seminiferous tubules $(293.06 \pm 45.25 \mu \mathrm{m}, n=5)$ when compared to CT pigs $(261.03 \pm 51.42 \mu \mathrm{m}, n=5)(p<0.01)$ and obviously increased numbers of germ and Sertoli cells within the seminiferous epithelium (Figure 1G). These results were consistent with previous reports that prepubertal hemicastration was shown to induce hypertrophy of the remaining testis through the rapid proliferation of Leydig cells and Sertoli cells [8,9] and demonstrated the successful establishment of a testosterone deficiency model in Yorkshire boars.

Subsequently, 30 semen samples were collected from HC and CT pigs ( $n=15$ per group) for routine examination. Hemicastration was found to decrease sperm density (172 \pm 46 million $/ \mathrm{mL}$ in $\mathrm{HC}$ versus $225 \pm 43$ million/mL in CT, $p<0.01)$, weaken sperm motility $(57.34 \pm 3.87 \%$ in $\mathrm{HC}$ versus $78.52 \pm 1.93 \%$ in $\mathrm{CT}, p<0.01$ ), and reduce three velocity parameters, including straight line velocity (VSL; $18.6 \pm 2.3 \mu \mathrm{m} / \mathrm{s}$ in HC versus $21.4 \pm 1.7 \mu \mathrm{m} / \mathrm{s}$ in CT, $p<0.01$ ), curvilinear velocity (VCL; $51.7 \pm 6.4 \mu \mathrm{m} / \mathrm{s}$ in HC versus $57.2 \pm 5.9 \mu \mathrm{m} / \mathrm{s}$ in $\mathrm{CT}, p<0.05$ ), and average path velocity (VAP; $26.8 \pm 2.6 \mu \mathrm{m} / \mathrm{s}$ in $\mathrm{HC}$ versus $28.3 \pm 2.9 \mu \mathrm{m} / \mathrm{s}$ in $\mathrm{CT}, p<0.05$ ) (Figure $1 \mathrm{H}-\mathrm{J}$ ). No obvious differences were observed in the amplitude of lateral head displacement (ALH) or motility parameter wobble (WOB) between the two groups (Figure $1 \mathrm{~K}, \mathrm{~L}$ ). Flow cytometry analysis indicated that hemicastration significantly reduced sperm cell viability $(88.34 \pm 2.77 \%$ in $\mathrm{HC}$ versus $96.35 \pm 2.65 \%$ in CT, $p<0.01)$ and induced apoptosis, which may be responsible for the reduced sperm density and motility (Figure 1M,N). Notably, extensive studies have indicated a significant negative correlation between sperm apoptosis and motility in vivo and in vitro [28-30]. These results indicated that testosterone deficiency by prepubertal hemicastration expectably reduced serum testosterone levels and induced a significant increase in sperm apoptosis and a dramatic decline in the sperm motility of Yorkshire boars. Moreover, the fluorescent terminal deoxynucleotidyl transferase-mediated dUTP nick end-labeling (TUNEL) assays showed that an obvious increase of cell apoptosis also occurred in the seminiferous epithelium of the remaining testis of the hemicastrated pigs (Figure 1O). Collectively, our results suggest that prepubertal hemicastration pigs compensate for the growth and development of their major organs at the expense of the normal development and physiological function of their remaining testis.

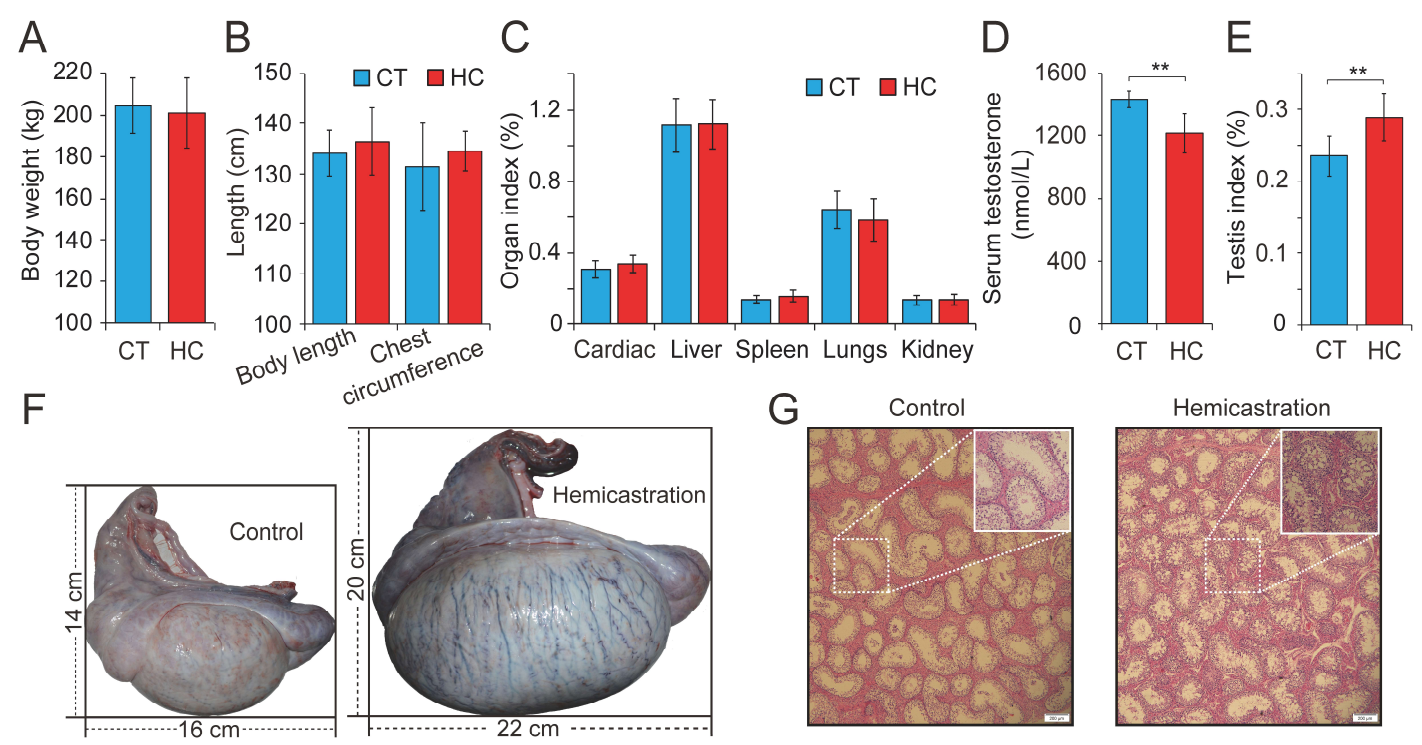

Figure 1. Cont. 

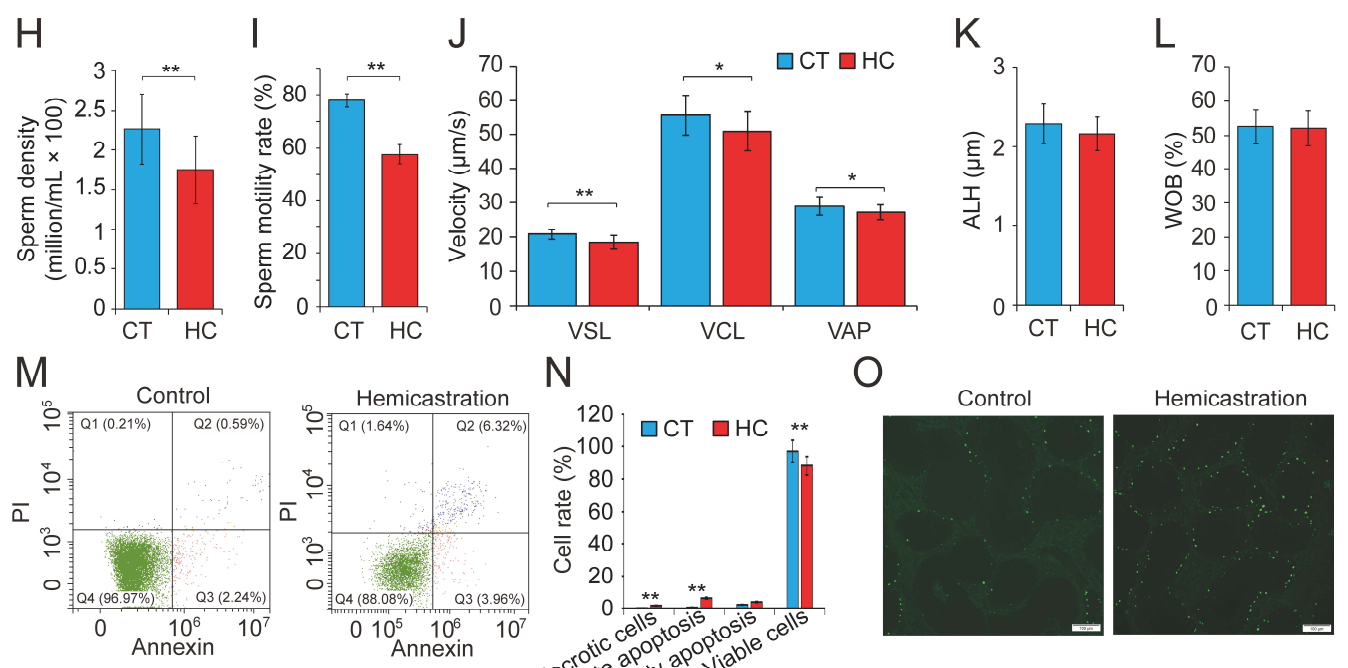

$\mathrm{N}$
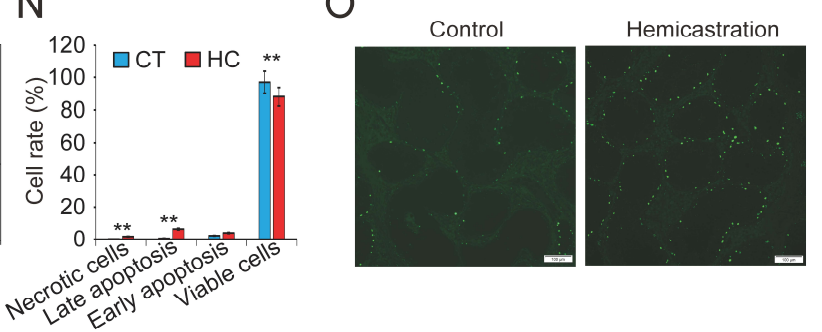

Figure 1. Altered profile of biological parameters between prepubertal hemicastration and control pigs. The influences of prepubertal hemicastration on porcine $(\mathbf{A})$ body weight, $(\mathbf{B})$ body size, and $(\mathbf{C})$ main organ indexes. Prepubertal hemicastration significantly affected the (D) serum testosterone level, (E) testis index, and (F) testis size. (G) Histological analysis of the testis of control and hemicastrated pigs. Bars $=200 \mu \mathrm{m} ; 100 \times$ magnification; hematoxylin-eosin staining. $(\mathbf{H})$ Sperm density of experimental pigs. (I) Sperm motility rate (\%) represents the percentage of sperm showing motility. (J) Three motility parameters, including the curvilinear velocity (VCL, $\mu \mathrm{m} / \mathrm{s})$, average path velocity (VAP, $\mu \mathrm{m} / \mathrm{s}$ ) and straight line velocity (VSL, $\mu \mathrm{m} / \mathrm{s}$ ), were assessed for both experimental pig groups. (K) Amplitude of lateral head displacement $(\mathrm{ALH}, \mu \mathrm{m})$ for both experimental pig groups. (L) The wobble (WOB, \%) measures the oscillation of the actual trajectory of sperm cells. (M,N) Sperm apoptosis rates of control and hemicastrated pigs were evaluated by flow cytometry analysis. (O) Apoptotic bodies in testicular tissues of control and hemicastrated pigs, detected as strongly green fluorescent cells. Bars $=100 \mu \mathrm{m}$; $200 \times$ magnification. CT and HC represent the prepubertally hemicastrated Yorkshire boars and normal controls, respectively. All data are expressed as means $\pm \mathrm{SD}$. ${ }^{*} p<0.05,{ }^{* *} p<0.01$.

\subsection{Testosterone Deficiency Dramatically Changes the Sperm miRNAome}

Recent research showed that miRNAs play an important role in maintaining semen quality and ensuring normal fertilization $[18,19]$. To systematically investigate the mechanism of the specific decline of sperm quality in hemicastrated pigs at the miRNA transcriptome level, we isolated sperm cells from HC and CT semen samples ( $n=3$ per group), then extracted and sequenced small RNA using an Illumina HiSeq platform for miRNA profiling. We identified a total of 180 known pre-miRNAs encoding 206 mature miRNAs in six libraries (Table S1). The length distribution of identified miRNAs was consistent with the canonical size range of mammalian miRNAs [31] (Figure 2A), confirming the reliability of our small RNA-seq results.

Hierarchic clustering analysis for all 206 known miRNAs showed that HC and CT pigs were perfectly clustered into two independent branches based on the sperm miRNA transcriptome, which reflected the repeatability of our experimental treatment (Figure 2B). Ranking analysis showed that, although $80 \%$ (8/10) of the top 10 high-expressed miRNAs were shared between HC and CT sperm libraries, they had different expression levels (Figure 2C). These results demonstrated that prepubertal hemicastration markedly altered the sperm miRNA expression profile, which may further result in the disruption of sperm motility. Furthermore, 16 DE miRNAs were identified in HC versus CT sperm (defined as those exhibiting a Benjamini-corrected $p$-value $\leq 0.05$ and a fold-change $>2$ or $<0.5$ in HC versus CT sperm) (Table S2). Subsequently, we used DIANA online software [32] for functional annotation of the sperm DE miRNAs. This revealed that the target genes of the DE miRNAs were mainly associated with the hypoxia-inducible factor-1 (HIF-1) signaling pathway, the cell cycle, 
and pathways involved in cell apoptosis, including the mTOR and p53 signaling pathways (Figure 2D). Notably, more than half of the sperm DE miRNAs (12/16, 75\%) were enriched in the p53 signaling pathway; these DE miRNAs directly target important mRNA transcripts that coordinate apoptosis and cell survival. Additionally, among the 16 DE miRNAs, we detected two miRNA families (miR-30 and let-7 families) and one miRNA cluster (miR-183 cluster) whose members exhibited highly similar downregulated expression patterns in $\mathrm{HC}$ versus $\mathrm{CT}$ sperm (Figure 2E). These results indicated the potentially similar effects of these miRNAs on sperm quality and male fertility. Although the members of the let-7 miRNA family have been recognized as efficient tumor suppressors [33,34], they also exhibited fertility-related functions in recent studies, such as the upregulation of let-7 members in porcine sperm with abnormal morphology and motility [35] and the similarly high abundance of let-7 members in the ovaries and testes of Portunus trituberculatus, indicating their essential roles in gonadal development and function [36]. Moreover, deregulated sperm miR-182 was reported to mediate the paternal heredity of diet-induced obesity and metabolic disorders in mice [37]. Taken together, these results suggest that these sperm DE miRNAs play a vital function in sperm survival and maintaining sperm quality.

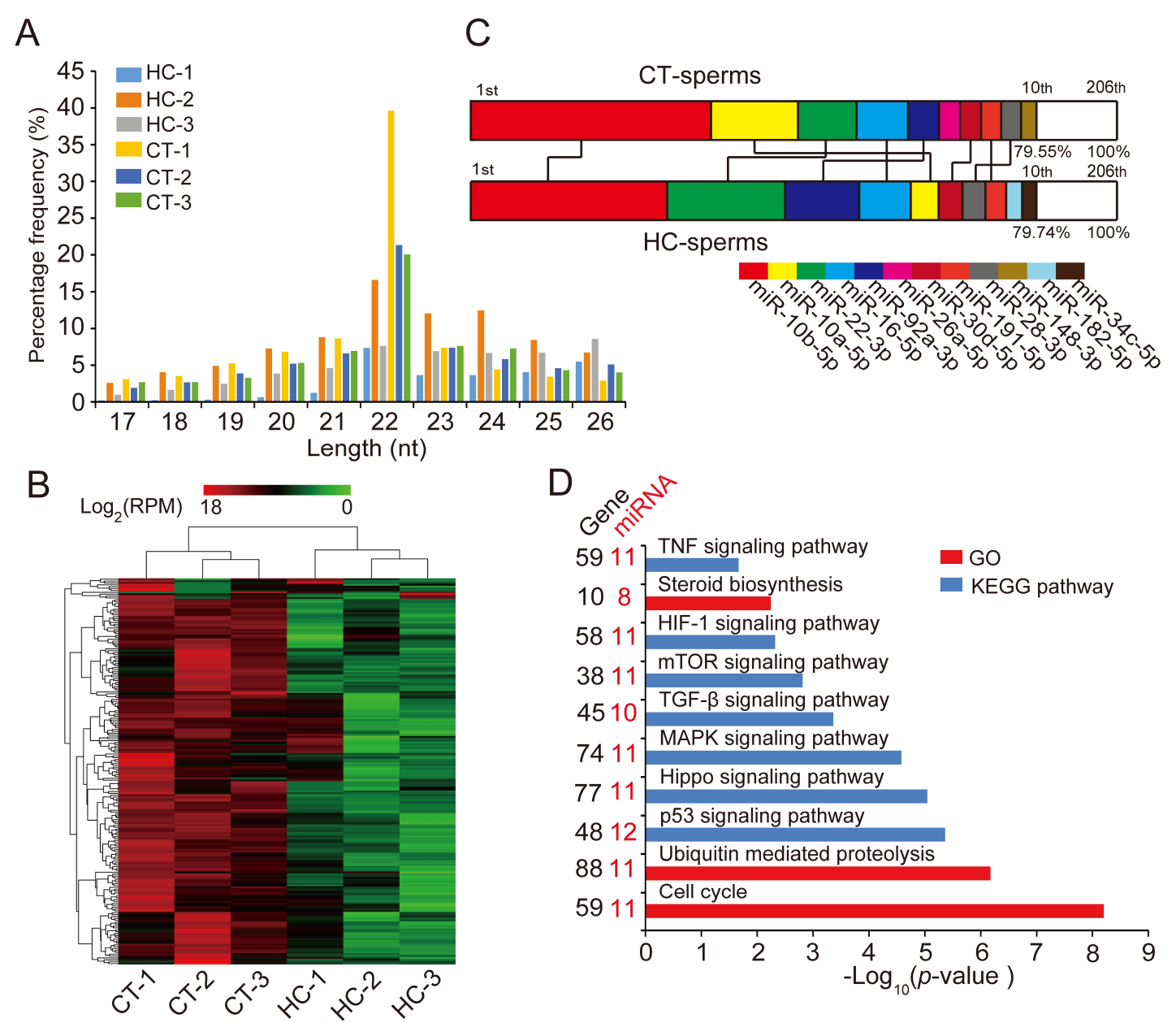

Figure 2. Cont. 

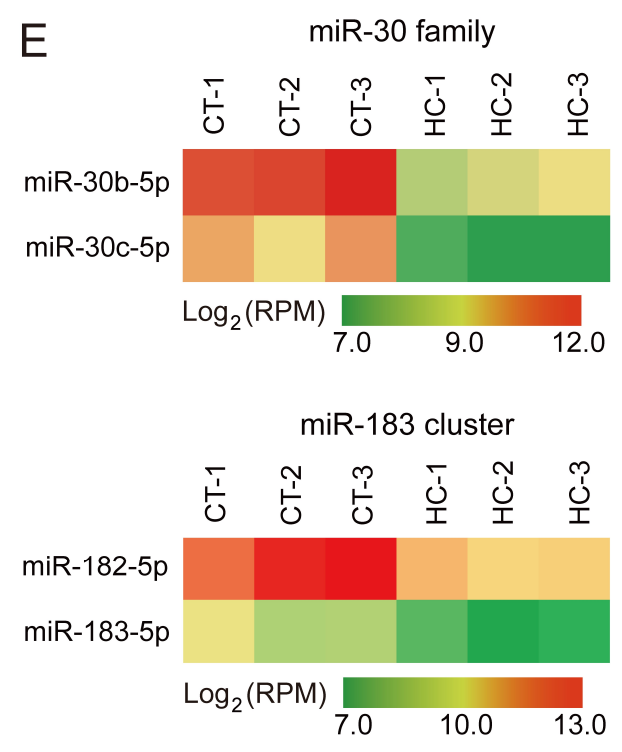

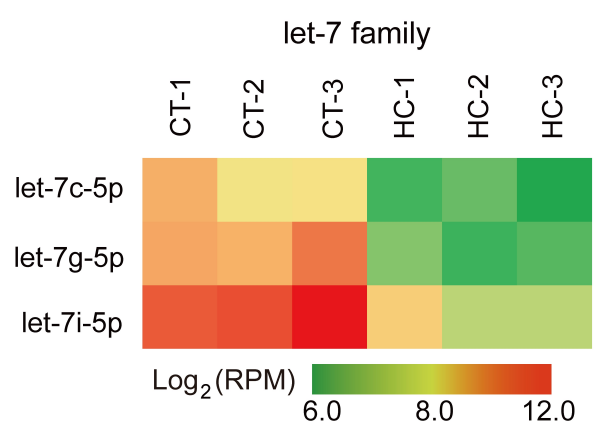

Figure 2. miRNA expression profiles of sperm cells in control and hemicastrated pigs. (A) The length distribution of identified miRNAs in all small RNA libraries. (B) Hierarchical clustering analysis for the expression of 206 known sperm miRNAs between control and hemicastrated pigs based on the Euclidean distance. Complete linkage hierarchic clustering was performed with the Euclidian distance measure. (C) Ranking analysis of the top 10 sperm miRNAs with the highest expression levels in control and hemicastrated pigs. The labels upper the bar represent the ranking of the top 10 miRNAs by expression, while the labels below the bar represent the accumulative $\%$ of the top 10 miRNAs in total read per million (RPM) of all expressed miRNAs. Seven miRNAs that are present in the top 10 position in both experimental groups are connected by lines. (D) Gene ontology (GO) and Kyoto Encyclopedia of Genes and Genomes (KEGG) pathway analysis of potential targets of the DE miRNAs. $p$-Values indicating the significance of enrichment were calculated by the Benjamini-corrected modified Fisher's exact test. (E) Heat maps of the expression pattern of the DE sperm miRNA families and a cluster in control and hemicastrated groups. CT and HC represent prepubertally hemicastrated Yorkshire boars and controls, respectively.

\subsection{Overexpression of $m i R-26 a-5 p$ and let-7g-5p Improves Sperm Quality}

To further investigate the biological effects of DE sperm miRNAs on sperm quality, we selected miR-26a-5p and let-7g-5p, which were significantly downregulated in HC sperm cells and predicted to participate in apoptosis, for functional verification. Previous studies showed that miR-26a-5p protects RGC-5 cells against $\mathrm{H}_{2} \mathrm{O}_{2}$-induced apoptosis [38], while let-7g-5p inhibits oxidized low-density lipoprotein (ox-LDL)-induced apoptosis in endothelial cells by targeting caspase-3 [39]. Gain- and loss-of-function assays were performed by transfection of the miRNA mimic (or mimic control), or inhibitor (or inhibitor control) in freshly collected semen samples. qRT-PCR results confirmed the effective overexpression and downregulation of miR-26a-5p in sperm transfected with the miRNA mimic and inhibitor, respectively $(p<0.01)$ (Figure 3A). Phenotypic parameters of sperm evaluated $8 \mathrm{~h}$ after transfection showed that miR-26a-5p significantly improved sperm quality, by augmenting VCL $(p<0.01)$, VSL $(p<0.05)$, and VAP $(p<0.05)$ (Figure 3B) and enhancing sperm motility $(p<0.05)$ (Figure 3C). No significant changes were observed in ALH, sperm density, WOB, linearity (LIN), or straightness (STR) (Figure 3D-G). Moreover, overexpression of miR-26a-5p significantly reduced the expression of its predicted target gene PTEN and two other apoptosis marker genes (caspase-3 and p53); whereas, it enhanced expression of the anti-apoptotic gene $\mathrm{Bcl}-2(p<0.01)$ (Figure $3 \mathrm{H})$. Similarly, the overexpression of let-7g-5p reduced sperm apoptosis and improved sperm motility (Figure S1A-H). These results highlighted the crucial role of miR-26a-5p and let-7g-5p in inhibiting sperm apoptosis and improving sperm motility. 
A

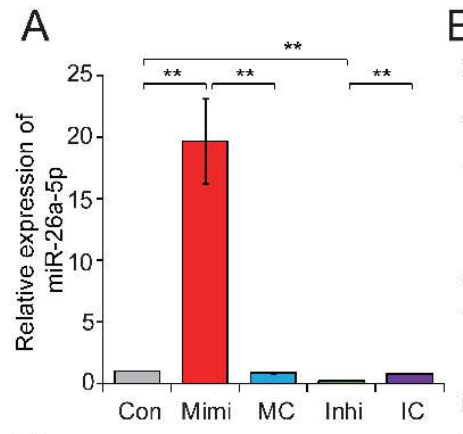

D

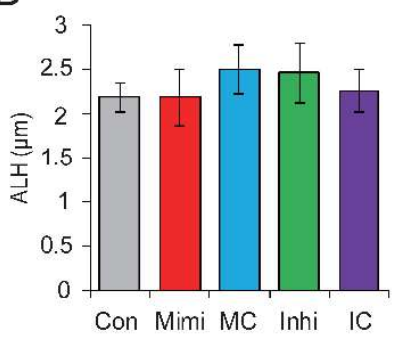

$\mathrm{B}$
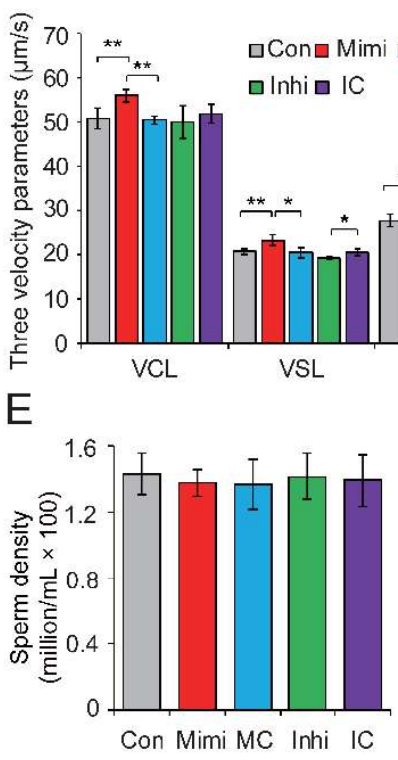

C

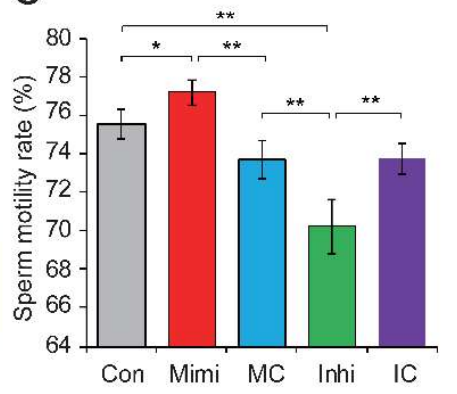

$\mathrm{F}$

G

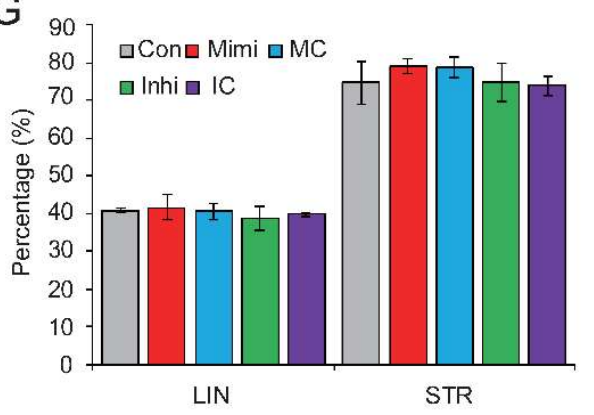

$\mathrm{H}$

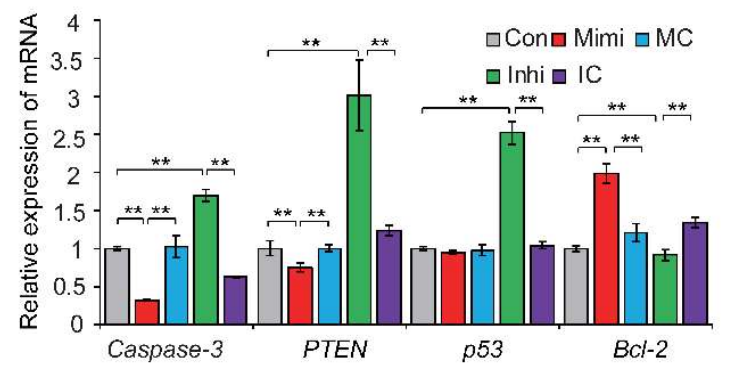

Figure 3. The miR-26a-5p-mediated regulation of sperm quality. (A) Relative expression levels of miR-26a-5p in control, mimic- and inhibitor-transfected sperm. (B) Effect of miR-26a-5p mimic and inhibitor on three velocity parameters of sperm cells, including curvilinear velocity (VCL, $\mu \mathrm{m} / \mathrm{s}$ ), average path velocity (VAP, $\mu \mathrm{m} / \mathrm{s}$ ) and straight line velocity (VSL, $\mu \mathrm{m} / \mathrm{s}$ ). (C) Effect of miR-26a-5p mimics and inhibitor on sperm motility rate (\%). No significant changes were observed in (D) amplitude of lateral head displacement $(\mathrm{ALH}, \mu \mathrm{m}),(\mathbf{E})$ sperm density (million $/ \mathrm{mL}),(\mathbf{F})$ motility parameter wobble (WOB, \%), or (G) linearity (LIN, \%) and STR (\%). (H) Effect of miR-26a-5p mimics and inhibitor on the expression levels of apoptosis-related genes. Con, control; Mimi, mimics; MC, mimic control; Inhi, inhibitor; IC, inhibitor control. CT and HC represent prepubertally hemicastrated Yorkshire boars and normal controls, respectively. Three independent experiments were performed in triplicate and all data are expressed as means $\pm \mathrm{SD}$. ${ }^{*} p<0.05,{ }^{* *} p<0.01$.

\subsection{PTEN and PMAIP1 Are Targets of miR-26a-5p and let-7g-5p, Respectively}

To explore the mechanism by which miR-26a-5p and let-7g-5p significantly improved the reduction of sperm quality, we used TargetScan [40] and RNAhybrid [41] analyses to predict PTEN and PMAIP1 as potential targets of miR-26a-5p and let-7i-5p. In the above gain- and loss-of-function assays, we found that both PTEN and PMAIP1 mRNA levels were significantly reduced when miR-26a-5p or let-7g-5p were overexpressed in sperm (Figure 3H and Figure S1D).

We next performed a dual luciferase assay to demonstrate the relationships between candidate miRNAs and their potential target genes. The dual luciferase recombinant plasmid (pmirGLO-mRNA) constructed for PTEN and PMAIP1 and mRNA and miRNA binding sites are shown in Figure 4A. Recombinant plasmid (with wild-type (Wt) or mutant (Mut) PTEN 3'-untranslated regions (UTR)) was co-transfected with a miR-26a-5p mimic into PK15 cells and the luciferase activity assay was 
performed $48 \mathrm{~h}$ after transfection. The upregulation of miR-26a-5p significantly repressed luciferase activity of the PTEN 3'-UTR reporter (0.82-fold change, $p=0.005$; Figure $4 \mathrm{~B})$, whereas this repression was markedly abolished when the miR-26a-5p binding site in PTEN was mutated. The co-transfection of Wt or Mut PMAIP1 5'-UTR and let-7g-5p mimics into PK15 cells showed that let-7g-5p weakened the luciferase activity of the Wt PMAIP1 5'-UTR reporter (0.595-fold change, $p<0.001$; Figure 4C). These results suggested that PTEN and PMAIP1 are the respective target genes of miR-26a-5p and let-7g-5p. MiR-26a-5p appears to directly target PTEN and inhibit sperm apoptosis, while let-7g-5p reduced sperm apoptosis by targeting PMAIP1, then enhanced sperm motility and improved sperm quality. Our results also revealed that let-7g-5p binds PMAIP1 $5^{\prime}$-UTR and exerts an inhibitor function. This is in keeping with previous reports that target mRNAs can be repressed as efficiently by miRNA binding sites in the $5^{\prime}$-UTR as in the $3^{\prime}$-UTR $[42,43]$.

A

\section{Recombinant vector:}

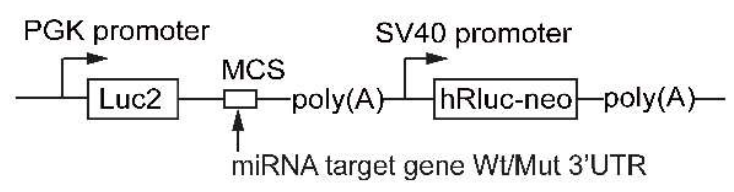

PTEN:

Pig Wt 3'-UTR: 5'-CAUCAUAAGAAACAAACUUGAA-3' ssc-miR-26a-5p: 3'-UCGGAUAGGACCUAAUGAACUUU-5' Pig Mut 3'-UTR: 5'-CAUCAUAAGAAACAAUCAUCAU-3'

\section{PMAIP1:}

Pig Wt 5'-UTR: 5'-CGCGCGCAGCCUGCUACCUGCAG-3' II IIIIII II ssc-let-7g-5p: 3'-UUGACAUGUUUGAUGAUGGA GU-5'

Pig Mut 5'-UTR: 5'-CGCGCGCAGCGAGCAAGCAGCUG-3'
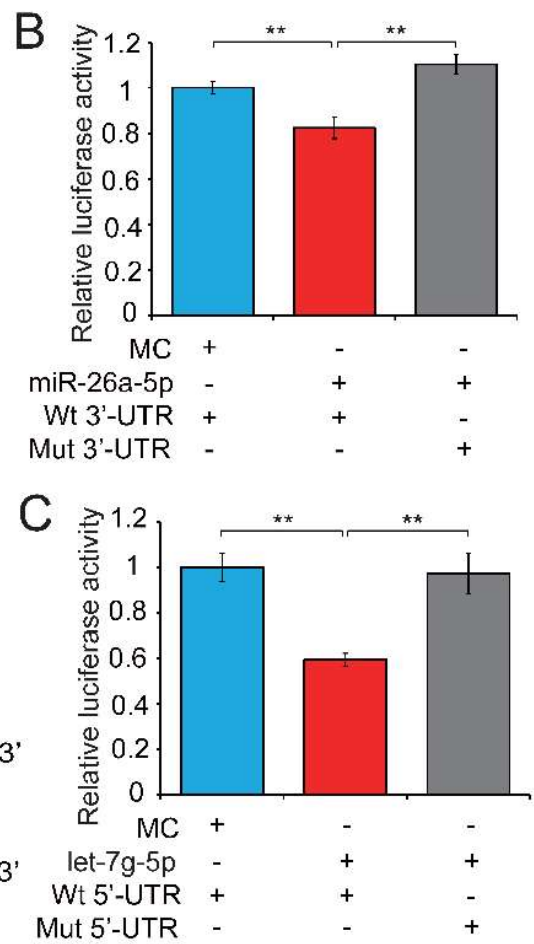

Figure 4. Testosterone-dependent miRNAs exert a pro-viability function by inhibiting pro-apoptotic factors. (A) Potential binding sites predicted by TargetScan [40] and RNAhybrid [41] for miR-26a-5p and let-7g-5p in the $3^{\prime}$-UTR of PTEN and the $5^{\prime}$-UTR of PMAIP1, respectively, and the mutant PTEN $3^{\prime}$-UTR and PMAIP1 $5^{\prime}$-UTR used in our study. A luciferase reporter assay was performed by co-transfecting luciferase reporter containing the $3^{\prime}$-UTR of PTEN and 5'-UTR of PMAIP1 (wild-type (Wt) or mutant (Mut)) with the mimic or control of miR-26a-5p and let-7g-5p into PK15 cells. The red underlined bases highlighted the miRNA seed sequences and their corresponding target sites in the mRNA UTR sequences. Luciferase activity was determined $48 \mathrm{~h}$ after transfection for (B) miR-26a-5p and (C) let-7g-5p. MC, mimics control. Three independent experiments were performed in triplicate and all data are expressed as means \pm SD. ${ }^{* *} p<0.01$.

PTEN (also known as MMAC-1) is a multifunctional phosphatase whose lipid phosphatase activity induces apoptosis and cell cycle arrest through phosphoinositol-3-kinase/Akt-dependent pathway [44]. Recent studies have shown that PTEN can also exert its pro-apoptotic function through a mitochondria-dependent pathway [45-47], in which the PTEN-Bax complex was translocated from the cytosol to the mitochondria, triggering the dysfunction of mitochondrial membrane and downstream apoptotic processes, including the release of several pro-apoptotic factors (e.g., cytochrome $c$ and ROS) and the activation of caspases (Caspase-3 and 9). PMAIP1, 
phorbol-12-myristate-13-acetate-induced protein 1 (also known as Noxa), is another pro-apoptotic factor [48]. It is a BH3-containing mitochondrial protein that is induced by p53 and contributes to p53-induced apoptosis by disrupting mitochondrial outer membrane integrity [49]. These indicate that both PTEN and PMAIP1 are implicated in the dysfunction of mitochondria and subsequent cell apoptosis, which will further affect the energy (ATP) production and sperm motility. Collectively, miR-26a-5p and let-7g-5p may indeed affect the sperm apoptosis and motility by targeting PTEN and PMAIP1, respectively.

\subsection{Significant Correlation between Sperm and Seminal Plasma Exosomes Regarding miRNA Expression}

Exosomes are nano-sized vesicles secreted by various cell types. They function as intercellular signaling agents by transferring their contents, which include miRNAs, mRNAs, lncRNAs, proteins, and lipids [50]. Previous reports have suggested that seminal plasma contains nano-sized vesicles such as prostasomes and epididymosomes. To explore the miRNA expression pattern between sperm and corresponding seminal plasma exosomes, we isolated exosomes from seminal plasma by ultracentrifugation and used atomic force microscopy to investigate them at the nanometer scale. The results indicate that porcine seminal plasma contains a large number of membranous vesicles with an approximate width of $110 \mathrm{~nm}$ and a height of $12 \mathrm{~nm}$ (Figure 5A), which exhibited a canonical morphological feature consisting of the exosomes derived from other bodily fluids (i.e., saliva and urine) and cell culture fluid [51-53]. Western blot analysis showed that the exosome-specific markers CD63 and TSG101 were specifically enriched, while the cellular specific marker tubulin was absent in the seminal plasma exosome-like vesicles, when compared to sperm cell lysates (Figure 5B). This result further confirmed the real identity of exosomes isolated from porcine seminal plasma. Moreover, the sperm-specific marker PRM-1/2 was shown by qRT-PCR to be highly expressed in sperm cells compared with seminal plasma exosomes (Figure 5C). These results demonstrate the presence of exosomes in seminal plasma, in keeping with the characteristics of typical exosomes listed by the International Society for Extracellular Vesicles [54]. Subsequent small RNA-seq using total RNA isolated from seminal plasma exosomes revealed extremely similar changes in the miRNA transcriptome of seminal plasma exosomes between $\mathrm{CT}$ and HC groups compared with sperm (Figure 5D, Table S3).

We further analyzed the Spearman's correlation of the miRNA expression profile between sperm and corresponding seminal plasma exosomes, which was found to be significantly positive (CT: $r=0.733, p<0.01$; HC: $r=0.719, p<0.01$ ) (Figure 5E). Furthermore, $20 \mathrm{DE}$ miRNAs were identified in seminal plasma exosomes between CT and HC groups (Table S4), of which five (including miR-26a-5p and let-7g-5p) overlapped between sperm and seminal plasma exosomes in HC versus CT pigs (Figure 5F). Interestingly, Spearman's correlation coefficients of expression levels for overlapping DE miRNAs in CT and HC pigs were 0.994 and 0.894 , respectively, which further emphasizes the close relationship between miRNAomes of sperm and seminal plasma exosomes and implies that testosterone deficiency may trigger fluctuations of this pattern. Prostasomes, one component of seminal plasma exosomes, are membrane-bound nanovesicles produced by acinar epithelial cells of the prostate gland. They are thought to play an important role in intercellular communication by transferring not only membrane components but also genetic material [55]. Recent studies suggested that prostasomes contain various bioactive molecules that improve semen quality $[56,57]$ and enhance the fertilizing ability of spermatozoa in humans and boar [55,58]. Similar to prostasomes, epididymosomes are secreted by epididymal epithelial cells in an apocrine manner and play a major role in post-testicular sperm maturation by transferring proteins that are crucial for sperm to acquire fertilizing ability $[59,60]$. Furthermore, epididymosomes function as intercellular signaling mediators throughout the bovine epididymis by releasing distinct miRNA repertoires into the intraluminal fluid [61]. In this study, we found that prepubertal hemicastration induced expression pattern changes of sperm and seminal plasma exosome miRNAs in adult pigs and that their miRNAomes were significantly correlated. Taken together with previous research, it is reasonable to speculate that testosterone deficiencies induce 
changes in the miRNA components of seminal plasma exosomes secreted by the genital tract, which in turn transfer these changes to sperm cells. These appear to partially underlie the sperm miRNAome changes, which are responsible for the decline of sperm motility in hemicastrated pigs.
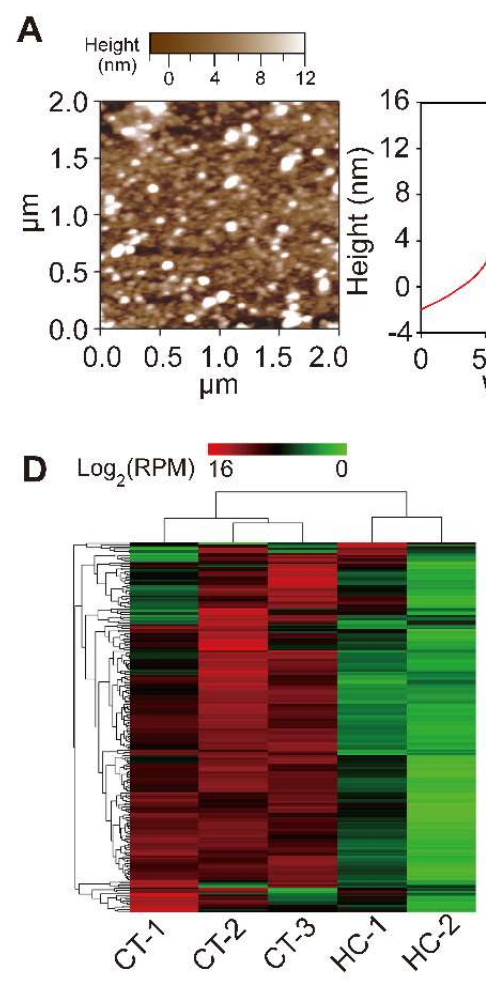

$\mathbf{F}$

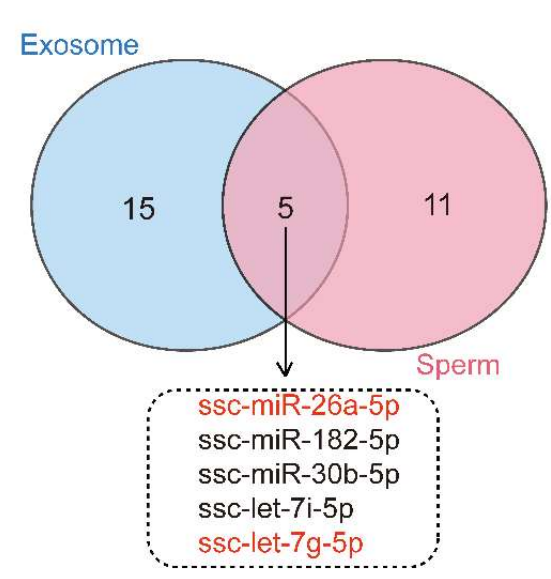

E
B C

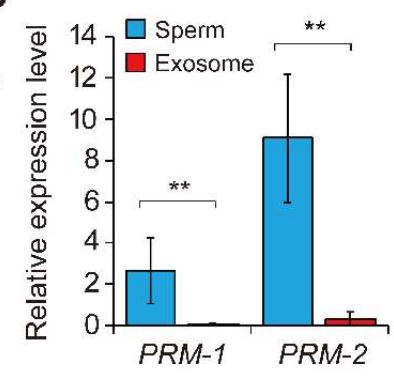

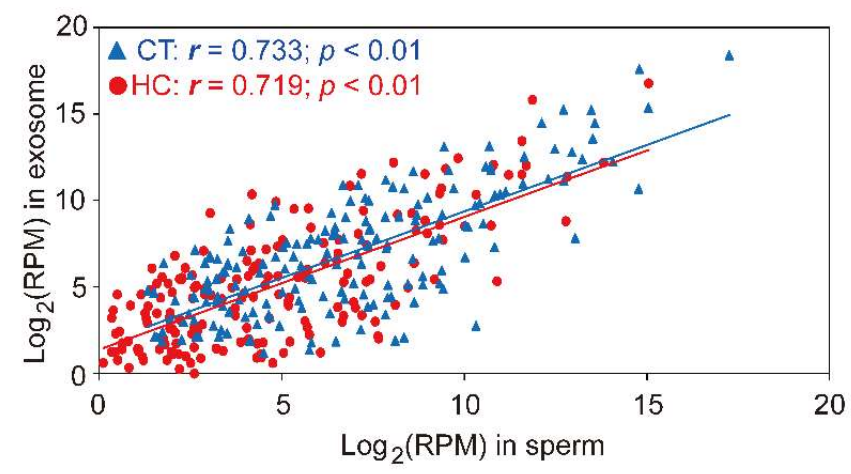

G

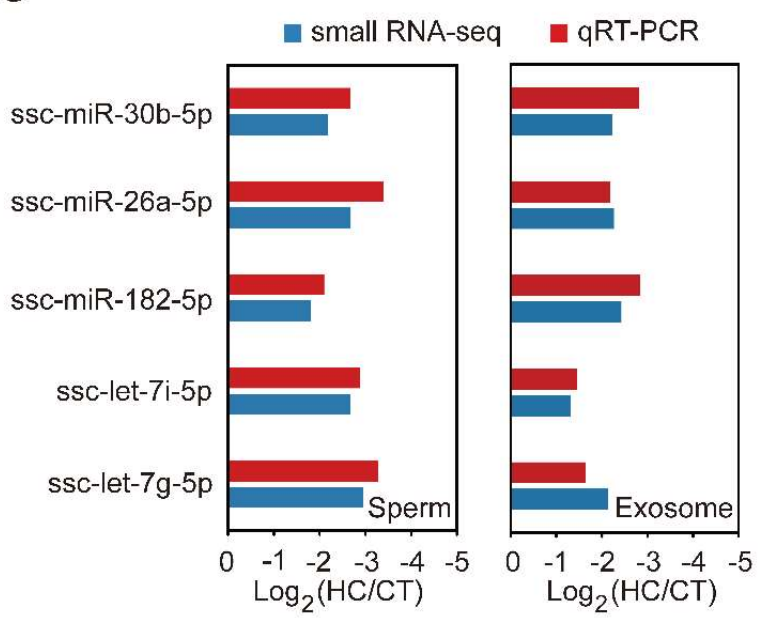

Figure 5. The comparison of miRNA data of sperm and seminal plasma exosomes. (A) Particle size distribution of CT-1 seminal plasma exosomes detected using atomic force microscopy. (B) Western blot analysis showing the enrichment of CD63 and CD81 and the absence of tubulin in CT-1 seminal plasma exosomes compared with sperm cell lysates. (C) The expression pattern of a sperm-specific marker, $P R M-1 / 2$, in sperm and seminal plasma exosomes. (D) Hierarchical clustering analysis for the expression of known exosomal miRNAs between control and hemicastrated pigs based on the Euclidean distance. (E) Spearman's correlation of miRNA expression profiles between sperm and corresponding seminal plasma exosomes. (F) Venn diagram of DE miRNAs between sperm and seminal plasma exosomes in the HC versus CT group. (G) qRT-PCR validation of expression changes of five overlapping DE miRNAs between HC and CT groups. Three independent qRT-PCR experiments were performed in triplicate. All data are expressed as means \pm SD. ${ }^{* *} p<0.01$. 


\subsection{Validation of Small RNA-Seq Results Using Real-Time PCR}

For validation purposes, we performed qRT-PCR for the expression of five overlapping DE miRNAs in CT and HC groups. The expression changes of miRNAs detected via qRT-PCR correlated with those in the small RNA-seq data (Spearman's $r=0.939, p=5.48 \times 10^{-5}$ ), which highlighted the reliability of the small RNA-seq approach (Figure 5G).

\section{Materials and Methods}

\subsection{Animal Materials and Experimental Treatments}

The experimental procedures used in this study were approved by the Institutional Animal Care and Use Committee of Sichuan Agricultural University (Approval Number DKY-S20153307, 15 November 2015). A total of 30 Yorkshire boars from 15 pairs of full siblings were used in this study. At the age of seven days, one pig from each pair was randomly selected to be hemicastrated (HC) under anesthesia and another one remained intact as a normal control (CT). All boars in the hemicastration group (HC) were subjected to unilateral orchiectomy via a midline scrotal incision to remove the unilateral (left) testis, as described in a previous study [62]. Moreover, sham surgery was performed in the control group (CT) at the same time. All boars were weaned at the age of 25 days and transferred to a nursery and fed in the same pen. At the age of 60 days, each boar in the HC and $\mathrm{CT}$ groups was fed in an independent pen and all boars were fed a diet of the same nutritional level throughout this study until slaughter (at 10 months old) [63].

\subsection{Measurement of Phenotypic Indexes}

The phenotypic indexes (the body weight and circumference length) of all experimental boars were measured before slaughter and the weight of their main organs (i.e., heart, liver, spleen, lung, kidney, and right testis) was measured immediately after slaughter and further used for the calculation of organ indexes (organ index $=$ organ weight/body weight $\times 100 \%$ ).

\subsection{Histomorphological Analysis}

The right testis was taken immediately after death from each of the sacrificed pigs and cut in half along with the longitudinal axis using a sterile operating knife. Then one block sample $(10 \times 10 \times 10 \mathrm{~mm} ; 1 \mathrm{~g})$ of parenchymal tissue from the central portion was excised for immediate formalin fixation ( $10 \%$ buffered formalin solution) and was then paraffin-embedded for structural evaluation. Three micrometer thick skin sections were obtained at $150 \mu \mathrm{m}$ intervals and were stained with hematoxylin-eosin. The mean diameter of a seminiferous tubule was calculated as the geometric average of the maximum and minimum diameter and 50 seminiferous tubules were measured for each sample in 10 randomly selected fields.

\subsection{TUNEL Staining}

The formalin-fixed, paraffin-embedded sections of testis from CT and HC pigs were analyzed using the Dead End ${ }^{\mathrm{TM}}$ Fluorometric TUNEL System (Promega, Madison, WI, USA). The assay was done according to the manufacturer's protocol. The fluorescein isothiocyanate (FITC) filter was used to find apoptotic cells, which showed up in green under a fluorescent microscope.

\subsection{Isolation of Sperm and Seminal Plasma Exosome from the Fresh Semen}

The ejaculates from each boar were collected using a manual collection method before slaughter [64] and only the spermatozoa-rich fractions of the ejaculates were collected and used in subsequent assays. Fresh semen was pre-diluted 1:1 with Beltsville Thawing Solution (BTS) and shipped on gel packs at about $17^{\circ} \mathrm{C}$ to the laboratory. Diluted semen was placed in 50-mL Falcon tubes and centrifuged at $1000 \times \mathrm{g}$ for $20 \mathrm{~min}$ at $4{ }^{\circ} \mathrm{C}$ to separate sperm and seminal plasma. Sperm 
pellets were washed twice using BTS at $1000 \times g$ for 20 min at $4{ }^{\circ} \mathrm{C}$ and incubated in somatic cell lysis buffer $(0.1 \%$ SDS, $0.5 \%$ Triton X-100) on ice for $40 \mathrm{~min}$ to remove somatic cells. Next, the sperm was pelleted by centrifugation at $600 \times g$ for $5 \mathrm{~min}$ and then immediately put into liquid nitrogen until use. Seminal plasma exosomes were isolated by ultra-centrifugation and filtration according to a previously described method with some modifications [65]. Briefly, the seminal plasma was centrifuged at $16,000 \times g$ for $1 \mathrm{~h}$ at $4{ }^{\circ} \mathrm{C}$ to remove cell debris; next, the supernatant was successively filtered using $0.45 \mu \mathrm{m}$ and $0.22 \mu \mathrm{m}$ filters and then centrifuged at $120,000 \times g$ for $60 \mathrm{~min}$ at $4{ }^{\circ} \mathrm{C}$. The pellets were washed by centrifugation $\left(120,000 \times g, 60 \mathrm{~min}, 4^{\circ} \mathrm{C}\right)$ twice using a wash buffer $(30 \mathrm{mM}$ TRIS, $130 \mathrm{mM} \mathrm{NaCl}$, pH 7.6). Finally, the seminal plasma exosome pellet was then re-suspended in $250 \mu \mathrm{L}$ nuclease free water and stored at $-80^{\circ} \mathrm{C}$ until use.

\subsection{Sperm Apoptosis Detection by Flow Cytometry}

An annexin V-FITC apoptosis detection kit was purchased from BD Pharmingen (San Diego, CA, USA) for the detection of sperm cell apoptosis by flow cytometry. A BTS fresh diluted semen sample (50 mL per pig) was centrifuged at $400 \times g$ for $12 \mathrm{~min}$, before the supernatant was discarded. We washed the collected sperm cells with ethyleneglycol-bis-( $\beta$-amino-ethyl)- $N, N^{\prime}$-tetraacetate (EGTA)/Hepes [66], collected sperm cells by centrifugation $400 \times g$ for $10 \mathrm{~min}$, and discarded supernatant cells. Samples were subjected to double-staining of Annexin V-FITC/propidium iodide (PI) for $10 \mathrm{~min}$ and then proceeded to flow cytometry assays.

\subsection{Atomic Force Microscopy (AFM)}

To characterize the morphology of seminal plasma exosomes, samples was diluted 1:100 in deionized water, followed by $20 \mathrm{~min}$ fixation in freshly cleaved mica sheets. In order to provide a surface coated with formulations of a suitable density, the mica sheets were rinsed three times with deionized water and further dried with a filter paper before detection. Surface morphological characteristics of semen plasma exosomes were examined under an MFP-3D atomic force microscope (Asylum Research, Santa Barbara, CA, USA), as described in a previous report [65].

\subsection{Western Blot Analysis}

Total proteins were extracted from the sperm and the seminal plasma exosomes as previously described [65]. The protein concentrations were determined by a BCA Protein Assay Kit (Thermo Scientific, Rockford, IL, USA). Thirty milligrams of protein was separated on an $8 \%$ SDS-PAGE gel and then transferred to nitrocellulose membranes. The defatted milk was used to block the membranes for $2 \mathrm{~h}$ at room temperature and then the blocked membranes were incubated for $2 \mathrm{~h}$ with either a 1:1000 dilution of rabbit anti-alpha Tubulin (Abcam, Cambridge, MA, USA), a 1:1000 dilution of mouse anti-CD63 (Abcam), or a 1:200 dilution of mouse anti-TSG101 (Abcam). The washed blots were incubated for $90 \mathrm{~min}$ at room temperature with goat anti-mouse or anti-rabbit immunoglobulins (IgG) horseradish peroxidase (HRP) conjugated secondary anti-bodies (diluted 1:5000 in TBS containing $0.1 \%$ Tween-20 (TBST)). The antigen-antibody bands were scanned and visualized using a GS-700 imaging densitometer (Bio-Rad Laboratories, Hercules, CA, USA) and analyzed using Image Studio version 4.0 software (LI-COR Biosciences, Lincoln, NE, USA).

\subsection{Sperm Quality Detection}

Semen samples were preheated to $37^{\circ} \mathrm{C}$ for $20 \mathrm{~min}$ and then $20 \mu \mathrm{L}$ were dropwise added to a pre-warmed cell Counting-Chamber (Makler; $10 \mathrm{~mm}$ depth; Sefi Medical Instruments, Haifa, Israel). The sperm quality parameters were examined at 100 $\times$ magnification with an Olympus BX41 microscope (Olympus Life Science Europe GMBH, Hamburg, Germany) equipped with phase-contrast optics and Sperm Class Analyzer 5 software (Microptic SL, Barcelona, Spain). A minimum of three replicates per seminal dose, with 1000 spermatozoa each, were analyzed. The motility parameters were evaluated in consecutive digitalized frames automatically acquired by Sperm Class Analyzer 5 
software (Microptic SL, Barcelona, Spain) in each field. The definition of motility parameters, including VCL, VAP, VSL, ALH, LIN, STR, and WOB, was according to previous reports [67,68].

\subsection{Small RNA Sequencing and Data Analysis}

Total RNA from sperm and seminal plasma exosomes were extracted using Trizol Reagent (Takara, Shiga, Japan). Evaluation of the quality and integrity of extracted RNA was carried out on an Agilent 2100 Bioanalyzer (Agilent Technologies, Redwood City, CA, USA). Small RNA-seq libraries were constructed and then sequenced on an Illumina HiSeq 2500 sequencing platform ((Illumina, Santa Clara, CA, USA). In brief, small RNA fractions (length from 18-30 nucleotides) were isolated from extracted total RNA by polyacrylamide gel electrophoresis (PAGE, 15\% Tris-borate-EDTA). The isolated small RNA fractions were ligated with $3^{\prime}$ and $5^{\prime}$ adaptors and reverse-transcribed to cDNA for PCR amplification. Finally, the PCR products were sequenced on Illumina HiSeq 2500 platform. The raw sequencing data from this study have been submitted to the NCBI Gene Expression Omnibus database (https:/ / www.ncbi.nlm.nih.gov / geo) under the accession number GSE111985.

To identify the porcine miRNAs, the initial sequence was subjected to a series of stringent filters (such as removing low-quality reads, repeated sequences, and adaptor sequences). Filtered sequences were then mapped to a reference pig genome (Sscrofa11.1) with stringent criteria (0 mismatch in the first $18 \mathrm{bp}$ ) using Bowtie software [69]. Next, the retained sequences were mapped to the known porcine precursor miRNAs recorded in miRBase 21.0 (www.mirbase.org) for miRNA annotation and expression profiling (maximum of two mismatches allowed), using the NCBI Local BLAST.

\subsection{Prediction and Functional Annotation of Sperm and Seminal Plasma Exosomes DE MiRNA Targets}

To explore the potential functions of the sperm DE miRNAs, candidate miRNAs target prediction and functional enrichment analysis were conducted using DIANA-mirPath v3.0 online software (http:/ /www.microrna.gr/miRPathv3) [32]. The predictions were made based on human mRNA-miRNA interactions using TarBase v7.0 (http:/ / diana.imis.athena-innovation.gr/DianaTools / index.php?r=tarbase/index), as porcine miRNAs were not available in the current version of the abovementioned algorithm. The gene ontology (GO) terms (including biological process (BP), cellular component (CC) and molecular function (MF)) and Kyoto Encyclopedia of Genes and Genomes (KEGG) pathways were selected for the functional annotation of predicted target genes.

\subsection{2. miRNA Transfection in Sperm}

On the basis of the small RNA-seq results and bioinformatics prediction, miR-26a-5p and let-7g-5p were selected to further verify their biological functions. The specific miRNA mimics and inhibitors were purchased from RIBOBIO (Guangzhou, China). Following the instructions in the user manual, sperm transfection was carried out using X-treme GENE siRNA Transfection Reagent (Roche, Basel, Switzerland). Briefly, the swim-up methods were used for preprocessing the diluent semen to obtain the portion containing high-quality sperm [57]. Separated sperm was washed twice using BTS at $1000 \times g$ for $20 \mathrm{~min}$. Next, five groups of sperm were prepared, including a control (no transfection); mimic-transfected; mimic control-transfected; inhibitor-transfected; and inhibitor control-transfected. The miRNA transfection solution and sperm medium were sufficiently mixed at a final concentration of $50 \mathrm{nM}$ for the mimic/mimic control-transfected groups, or $100 \mathrm{nM}$ for the inhibitor/inhibitor control-transfected groups. All groups were placed at $17^{\circ} \mathrm{C}$ for $8 \mathrm{~h}$ and then used for the following experiment.

\subsection{Dual Luciferase Reporter Assay}

The potential binding sites of miR-26a-5p and let-7g-5p in porcine PTEN and PMAIP1 mRNA sequences were predicted by TargetScan [40] and RNAhybrid [41], respectively. Luciferase activity assays were performed to evaluate a relationship between candidate miRNA and its potential target genes. In brief, the potentially targeted mRNAs (PTEN and PMAIP1) containing binding sites of 
miR-26a-5p and let-7g-5p, respectively, were synthesized by Tsingke (Chengdu, China) (Figure 4A). The sequences were cloned into the $3^{\prime}$ end of the firefly (luc2) luciferase reporter gene of the pmirGLO plasmid (Promega, Madison, WI, USA). Porcine kidney cells line (PK15) were cultured in 24-well plates and when the cells reached about $70 \%$ confluence, the recombinant pmirGLO vector was co-transfected with ssc-miR-26a-5p/ssc-let-7g-5p mimics or negative control oligos into these cells by Lipofectamine 3000 (Invitrogen, Carlsbad, CA, USA). PK15 cells were collected $48 \mathrm{~h}$ after the transfection and dual-luciferase activity was measured using the Dual-Luciferase Reporter Assay System kit (Promega), according to the manufacturer's instructions.

\subsection{4. $q R T-P C R$}

Total RNA was isolated from the sperm and the seminal plasma exosomes using TRIzol Reagent (Invitrogen), following the instructions in the user manual. The reverse transcription of mRNA and miRNA were carried out by PrimeScript RT reagent Kit (Takara, Dalian, China) with gDNA Eraser and Mir-X ${ }^{\mathrm{TM}}$ miRNA First Strand Synthesis Kit (Takara), respectively. The qRT-PCR was carried out on a CFX96 detection system (Bio-Rad Laboratories) with a SYBR Premix Ex Taq kit (Takara). All reactions were performed in triplicate and the thermal cycling parameters were as follows: 5 min at $95^{\circ} \mathrm{C}$, followed by 40 cycles of three-step amplification $\left(15 \mathrm{~s}\right.$ at $95^{\circ} \mathrm{C}, 15 \mathrm{~s}$ at $60^{\circ} \mathrm{C}$, and $30 \mathrm{~s}$ at $\left.72{ }^{\circ} \mathrm{C}\right)$. Relative expression levels of mRNAs and miRNAs were normalized by the expression of GAPDH and U6, respectively, and were calculated using the comparative $2-\Delta \Delta \mathrm{Ct}$ method [70]. Primer sequences used in this study are shown in Table S5. All primers used in this study were synthesized by Tsingke (Chengdu, China).

\subsection{Statistical Analysis}

For small RNA-seq data, we used the freely available R software [71] to analyze the difference in miRNAs expression. Statistical significance was calculated using a paired, two-tailed $t$-test. The computed $p$-values for the $t$-test were adjusted with the use of Benjamini-Hochberg false discovery rate (FDR) [72] correction. Differentially expressed miRNAs were defined as those exhibiting a Benjamini-corrected $p$-value $\leq 0.05$ and a fold-change $>2$ or $<0.5$ in HC versus CT.

For other data, one way ANOVA with Tukey's post hoc test and Student's $t$-test were employed to evaluate the statistical significance for comparisons of multiple groups and two groups, respectively, using SPSS 19.0 software (SPSS Inc., Chicago, IL, USA).

\section{Conclusions}

In this study, we carried out hemicastration in prepubertal Yorkshire boars and successfully established a testosterone deficiency model, which showed obvious compensatory hyperplasia in the remaining testis and a significant enhancement of sperm apoptosis accompanied by a dramatic decline in sperm motility. Using the small RNA-seq approach, we compared miRNA profiles of sperm cells between HC and CT boars and revealed that DE miRNAs were mainly enriched in pathways involved in cell apoptosis, including mTOR and p53 signaling pathways. Furthermore, gain- and loss-of-function analyses and dual luciferase assays demonstrated that endogenous miR-26a-5p and let-7g-5p have potential anti-apoptotic and pro-survival functions in sperm cells by targeting PTEN and PMAIP1 genes. Further comparisons revealed similarities in miRNA profiles between seminal plasma exosomes and sperm cells, both in HC and CT groups. Our study revealed that miRNAs in sperm cells and seminal plasma exosomes have important functions in the male reproductive system, which could be exploited for future treatments or novel diagnostic markers for male infertility.

Supplementary Materials: Supplementary materials can be found at http:/ / www.mdpi.com/1422-0067/19/4/ 1233/s1.

Acknowledgments: This work was supported by grants from the National Natural Science Foundation of China (31530073, 31601918, 31772576 and 31522055), the Sichuan Province \& Chinese Academy of Science of Science \& Technology Cooperation Project (2017JZ0025), the Program for Innovative Research Team of Sichuan 
Province (2015TD0012), the Science \& Technology Support Program of Sichuan (2016NYZ0042), the Science \& Technology Major Projects of Sichuan (2017NZDZX0002), the Earmarked Fund for China Agriculture Research System (CARS-35-01A) and the District-School cooperation project from Yucheng District, Ya'an City, Sichuan Province, China.

Author Contributions: Jideng Ma and Mingzhou Li conceived and designed the experiments; Jideng Ma, Jinwei Zhang, Yu Fan, Zihui Hu, Wanling Qiu, and Keren Long performed the experiments; Siyuan Feng, Qianzi Tang, and Long Jin analyzed the data; Xun Wang, Qi Zhou, Yiren Gu, Weihang Xiao, Lingyan Liu, and Xuewei Li contributed reagents/materials/analysis tools; Jideng Ma, Yu Fan, Jinwei Zhang, and Mingzhou Li wrote the paper.

Conflicts of Interest: The authors declare no conflict of interest.

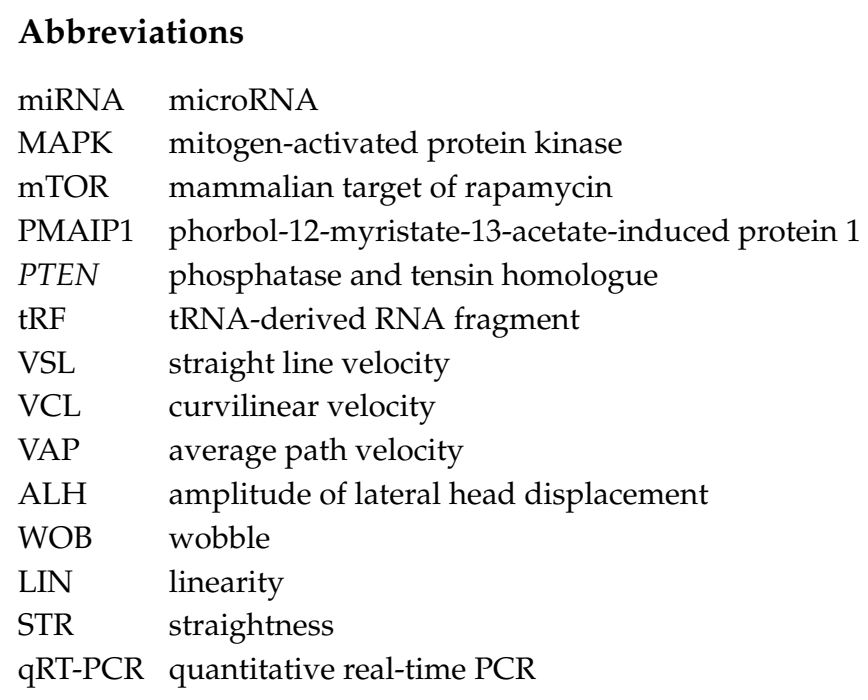

\section{References}

1. Jan, S.Z.; Hamer, G.; Repping, S.; de Rooij, D.G.; van Pelt, A.M.; Vormer, T.L. Molecular control of rodent spermatogenesis. Biochim. Biophys. Acta 2012, 1822, 1838-1850. [CrossRef] [PubMed]

2. Huhtaniemi, I.; Toppari, J. Endocrine, paracrine and autocrine regulation of testicular steroidogenesis. Adv. Exp. Med. Biol. 1995, 377, 33-54. [PubMed]

3. Ryan, C.P.; Mcdade, T.W.; Gettler, L.T.; Eisenberg, D.T.; Rzhetskaya, M.; Hayes, M.G.; Kuzawa, C.W. Androgen receptor cag repeat polymorphism and hypothalamic-pituitary-gonadal function in filipino young adult males. Am. J. Hum. Biol. 2016, 29. [CrossRef] [PubMed]

4. Dedov, I.I.; Melnichenko, G.A.; Rozhivanov, R.V.; Kurbatov, D.G. Guidelines for the diagnosis and treatment of testosterone deficiency (hypogonadism) in male patients. Probl. Endokrinologii 2017, 62, 78-80. [CrossRef]

5. Chang, C.; Chen, Y.T.; Yeh, S.D.; Xu, Q.; Wang, R.S.; Guillou, F.; Lardy, H.; Yeh, S. Infertility with defective spermatogenesis and hypotestosteronemia in male mice lacking the androgen receptor in sertoli cells. Proc. Natl. Acad. Sci. USA 2004, 101, 6876-6881. [CrossRef] [PubMed]

6. Wang, R.S.; Yeh, S.; Tzeng, C.R.; Chang, C. Androgen receptor roles in spermatogenesis and fertility: Lessons from testicular cell-specific androgen receptor knockout mice. Endocr. Rev. 2009, 30, 119-132. [CrossRef] [PubMed]

7. Taha, M.B.; Noakes, D.E.; Allen, W.E. Hemicastration and castration in the beagle dog; the effects on libido, peripheral plasma testosterone concentrations, seminal characteristics and testicular function. J. Small Anim. Pract. 2010, 23, 279-285. [CrossRef]

8. Lunstra, D.D.; Wise, T.H.; Ford, J.J. Sertoli cells in the boar testis: Changes during development and compensatory hypertrophy after hemicastration at different ages. Biol. Reprod. 2003, 68, 140-150. [CrossRef] [PubMed]

9. Berger, T.; Conley, A. Reduced endogenous estrogen and hemicastration interact synergistically to increase porcine sertoli cell proliferation. Biol. Reprod. 2014, 90, 114. [CrossRef] [PubMed]

10. Tsutsui, T.; Kurita, A.; Kirihara, N.; Hori, T.; Kawakami, E. Testicular compensatory hypertrophy related to hemicastration in prepubertal dogs. J. Vet. Med. Sci. 2004, 66, 1021-1025. [CrossRef] [PubMed] 
11. Johnson, L.; Neaves, W.B. Enhanced daily sperm production in the remaining testis of aged rats following hemicastration. J. Androl. 1983, 4, 162-166. [CrossRef] [PubMed]

12. Carthew, R.W.; Sontheimer, E.J. Origins and mechanisms of miRNAs and siRNAs. Cell 2009, 136, $642-655$. [CrossRef] [PubMed]

13. Winter, J.; Jung, S.; Keller, S.; Gregory, R.I.; Diederichs, S. Many roads to maturity: MicroRNA biogenesis pathways and their regulation. Nat. Cell Biol. 2009, 11, 228-234. [CrossRef] [PubMed]

14. Tang, F.; Kaneda, M.; O'Carroll, D.; Hajkova, P.; Barton, S.C.; Sun, Y.A.; Lee, C.; Tarakhovsky, A.; Lao, K.; Surani, M.A. Maternal microRNAs are essential for mouse zygotic development. Genes Dev. 2007, 21, 644-648. [CrossRef] [PubMed]

15. Carleton, M.; Cleary, M.A.; Linsley, P.S. MicroRNAs and cell cycle regulation. Cell Cycle 2007, 6, 2127-2132. [CrossRef] [PubMed]

16. Lakshmipathy, U.; Love, B.; Goff, L.A.; Jörnsten, R.; Graichen, R.; Hart, R.P.; Chesnut, J.D. MicroRNA expression pattern of undifferentiated and differentiated human embryonic stem cells. Stem Cells Dev. 2007, 16, 1003-1016. [CrossRef] [PubMed]

17. Ounsa, M.A.A.G.E.; Mohamed, E.Y.; Elamin, M.I.; Abdalla, S.M.; Gerais, A.S. Pattern of semen fluid abnormalities in male partners of infertile couples in Khartoum, Sudan. Sudan Med. Monit. 2011, 6, 215-220.

18. Abu-Halima, M.; Hammadeh, M.; Schmitt, J.; Leidinger, P.; Keller, A.; Meese, E.; Backes, C. Altered microRNA expression profiles of human spermatozoa in patients with different spermatogenic impairments. Fertil. Steril. 2013, 99, 1249-1255. [CrossRef] [PubMed]

19. Liu, W.M.; Pang, R.T.; Chiu, P.C.; Wong, B.P.; Lao, K.; Lee, K.F.; Yeung, W.S. Sperm-borne microRNA-34c is required for the first cleavage division in mouse. Proc. Natl. Acad. Sci. USA 2012, 109, 490-494. [CrossRef] [PubMed]

20. Saez, F.; Frenette, G.; Sullivan, R. Epididymosomes and prostasomes: Their roles in posttesticular maturation of the sperm cells. J. Androl. 2003, 24, 149-154. [CrossRef] [PubMed]

21. Poliakov, A.; Spilman, M.; Dokland, T.; Amling, C.L.; Mobley, J.A. Structural heterogeneity and protein composition of exosome-like vesicles (prostasomes) in human semen. Prostate 2009, 69, 159-167. [CrossRef] [PubMed]

22. Kovak, M.R.; Saraswati, S.; Schoen, D.J.; Diekman, A.B. Investigation of galectin-3 function in the reproductive tract by identification of binding ligands in human seminal plasma. Am. J. Reprod. Immunol. 2014, 72, 403-412. [CrossRef] [PubMed]

23. Sullivan, R.; Saez, F.; Girouard, J.; Frenette, G. Role of exosomes in sperm maturation during the transit along the male reproductive tract. Blood Cells Mol. Dis. 2005, 35, 1-10. [CrossRef] [PubMed]

24. Gatti, J.L.; Métayer, S.; Belghazi, M.; Dacheux, F.; Dacheux, J.L. Identification, proteomic profiling, and origin of ram epididymal fluid exosome-like vesicles. Biol. Reprod. 2005, 72, 1452-1465. [CrossRef] [PubMed]

25. Kumar, P.; Kuscu, C.; Dutta, A. Biogenesis and function of transfer RNA-related fragments (tRFs). Trends Biochem. Sci. 2016, 41, 679-689. [CrossRef] [PubMed]

26. Chen, Q.; Yan, M.; Cao, Z.; Li, X.; Zhang, Y.; Shi, J.; Feng, G.H.; Peng, H.; Zhang, X.; Zhang, Y. Sperm tsRNAs contribute to intergenerational inheritance of an acquired metabolic disorder. Science 2016, 351, 397-400. [CrossRef] [PubMed]

27. Sharma, U.; Conine, C.C.; Shea, J.M.; Boskovic, A.; Derr, A.G.; Bing, X.Y.; Belleannee, C.; Kucukural, A.; Serra, R.W.; Sun, F. Biogenesis and function of tRNA fragments during sperm maturation and fertilization in mammals. Science 2016, 351, 391-396. [CrossRef] [PubMed]

28. Grunewald, S.; Paasch, U.; Said, T.M.; Sharma, R.K.; Agarwal, A.; Glander, H.J. Modulation of mitochondrial mediated apoptosis in ejaculated human spermatozoa and its impact on sperm motility. Fertil. Steril. 2004, 82, S285. [CrossRef]

29. Li, D.; Yuan, D.; Zhang, L.; Qiao, P.; Liang, X.; Chang, B. Increase of apoptosis and decrease of sperm motility induced by oxidative stress after exposed to butyl p-hydroxybenzoate. J. Hyg. Res. 2017, 46, 196-200.

30. Perdichizzi, A.; Nicoletti, F.; La, V.S.; Barone, N.; D’Agata, R.; Vicari, E.; Calogero, A.E. Effects of tumour necrosis factor-alpha on human sperm motility and apoptosis. J. Clin. Immunol. 2008, 28, 94. [CrossRef]

31. Cui, L.; Guo, X.; Qi, Y.; Qi, X.; Ge, Y.; Shi, Z.; Wu, T.; Shan, J.; Shan, Y.; Zhu, Z. Identification of microRNAs involved in the host response to enterovirus 71 infection by a deep sequencing approach. J. Biomed. Biotechnol. 2015, 2010, 425939. [CrossRef] [PubMed] 
32. Vlachos, I.S.; Zagganas, K.; Paraskevopoulou, M.D.; Georgakilas, G.; Karagkouni, D.; Vergoulis, T.; Dalamagas, T.; Hatzigeorgiou, A.G. Diana-mirpath v3.0: Deciphering microRNA function with experimental support. Nucleic Acids Res. 2015, 43, 460-466. [CrossRef] [PubMed]

33. Anastasiadou, E.; Jacob, L.S.; Slack, F.J. Non-coding RNA networks in cancer. Nat. Rev. Cancer 2018, 18, 5-18. [CrossRef] [PubMed]

34. Adams, B.D.; Anastasiadou, E.; Esteller, M.; He, L.; Slack, F.J. The inescapable influence of noncoding RNAs in cancer. Cancer Res. 2015, 75, 5206-5210. [CrossRef] [PubMed]

35. Curry, E.; Safranski, T.J.; Pratt, S.L. Differential expression of porcine sperm microRNAs and their association with sperm morphology and motility. Theriogenology 2011, 76, 1532-1539. [CrossRef] [PubMed]

36. Meng, X.; Zhang, X.; Li, J.; Liu, P. Identification and comparative profiling of ovarian and testicular microRNAs in the swimming crab Portunus trituberculatus. Gene 2018, 640, 6-13. [CrossRef] [PubMed]

37. Valérie, G.; Sandra, F.; De Abreu Fernandes, D.A.; Marie-Alix, D.; Jean-Jacques, R.; Minoo, R. RNA-mediated paternal heredity of diet-induced obesity and metabolic disorders. Sci. Rep. 2015, 5, 18193. [CrossRef]

38. Kang, Y.; Jia, P.; Zhao, H.; Hu, C.; Yang, X. MicroRNA-26a overexpression protects RGC-5 cells against H2O2-induced apoptosis. Biochem. Biophys. Res. Commun. 2015, 460, 164-169. [CrossRef] [PubMed]

39. Zhang, Y.; Chen, N.; Zhang, J.; Tong, Y. Hsa-let-7g miRNA targets caspase-3 and inhibits the apoptosis induced by ox-ldl in endothelial cells. Int. J. Mol. Sci. 2013, 14, 22708-22720. [CrossRef] [PubMed]

40. TargetScanHuman. Available online: http://www.targetscan.org/vert_72/ (accessed on 20 March 2018).

41. Krüger, J.; Rehmsmeier, M. RNAhybrid: MicroRNA target prediction easy, fast and flexible. Nucleic Acids Res. 2006, 34, 451-454. [CrossRef] [PubMed]

42. Lytle, J.R.; Yario, T.A.; Steitz, J.A. Target mRNAs are repressed as efficiently by microRNA-binding sites in the $5^{\prime}$ UTR as in the 3'UTR. Proc. Natl. Acad. Sci. USA 2007, 104, 9667-9672. [CrossRef] [PubMed]

43. Lee, I.; Ajay, S.S.; Yook, J.I.; Kim, H.S.; Hong, S.H.; Kim, N.H.; Dhanasekaran, S.M.; Chinnaiyan, A.M.; Athey, B.D. New class of microRNA targets containing simultaneous 5'-UTR and $3^{\prime}$-UTR interaction sites. Genome Res. 2009, 19, 1175-1183. [CrossRef] [PubMed]

44. Weng, L.; Brown, J.; Eng, C. Pten induces apoptosis and cell cycle arrest through phosphoinositol-3-kinase/ Akt-dependent and -independent pathways. Hum. Mol. Genet. 2001, 10, 237-242. [CrossRef] [PubMed]

45. Zhu, Y.; Hoell, P.; Ahlemeyer, B.; Krieglstein, J. Pten: A crucial mediator of mitochondria-dependent apoptosis. Apoptosis 2006, 11, 197-207. [CrossRef] [PubMed]

46. Missiroli, S.; Morganti, C.; Giorgi, C.; Pinton, P. Methods to study pten in mitochondria and endoplasmic reticulum. Methods Mol. Biol. 2015, 1388, 187-212.

47. Bononi, A.; Bonora, M.; Marchi, S.; Missiroli, S.; Poletti, F.; Giorgi, C.; Pandolfi, P.P.; Pinton, P. Identification of pten at the er and mams and its regulation of $\mathrm{Ca}^{2+}$ signaling and apoptosis in a protein phosphatase-dependent manner. Cell Death Differ. 2013, 20, 1631-1643. [CrossRef] [PubMed]

48. Kuo, K.K.; Chen, Y.L.; Chen, L.R.; Li, C.F.; Lan, Y.H.; Chang, F.R.; Wu, Y.C.; Shiue, Y.L. Involvement of phorbol-12-myristate-13-acetate-induced protein 1 in goniothalamin-induced TP53-dependent and -independent apoptosis in hepatocellular carcinoma-derived cells. Toxicol. Appl. Pharmacol. 2011, 256, 8-23. [CrossRef] [PubMed]

49. Sun, Y.; Leaman, D.W. Phorbol 12-myristate 13 acetate-induced protein-1 (pmaip-1; human noxa) is a critical intermediate in double-stranded RNA-induced apoptosis in tumor cell lines. Cancer Res. 2004, 64, 745.

50. Valadi, H.; Ekström, K.; Bossios, A.; Sjöstrand, M.; Lee, J.J.; Lötvall, J.O. Exosome-mediated transfer of mrnas and microRNAs is a novel mechanism of genetic exchange between cells. Nat. Cell Biol. 2007, 9, 654-659. [CrossRef] [PubMed]

51. Liu, T.; Mendes, D.E.; Berkman, C.E. Functional prostate-specific membrane antigen is enriched in exosomes from prostate cancer cells. Int. J. Oncol. 2014, 44, 918-922. [CrossRef] [PubMed]

52. Palanisamy, V.; Sharma, S.; Deshpande, A.; Zhou, H.; Gimzewski, J.; Wong, D.T. Nanostructural and transcriptomic analyses of human saliva derived exosomes. PLoS ONE 2010, 5, e8577. [CrossRef] [PubMed]

53. Munich, S.; Sobovujanovic, A.; Buchser, W.J.; Beerstolz, D.; Vujanovic, N.L. Dendritic cell exosomes directly kill tumor cells and activate natural killer cells via tnf superfamily ligands. Oncoimmunology 2012, 1, 1074-1083. [CrossRef] [PubMed]

54. Takahiro, O. Secretory microRNAs by exosomes as a versatile communication tool. Dent. Med. Res. 2012, 32, $158-161$. 
55. Ronquist, G. Prostasomes are mediators of intercellular communication: From basic research to clinical implications. J. Intern. Med. 2012, 271, 400-413. [CrossRef] [PubMed]

56. Arienti, G.; Carlini, E.; Nicolucci, A.; Cosmi, E.V.; Santi, F.; Palmerini, C.A. The motility of human spermatozoa as influenced by prostasomes at various ph levels. Biol. Cell 1999, 91, 51-54. [CrossRef] [PubMed]

57. Fabiani, R.; Johansson, L.; Lundkvist, O.; Ronquist, G. Enhanced recruitment of motile spermatozoa by prostasome inclusion in swim-up medium. Hum. Reprod. 1994, 9, 1485-1489. [CrossRef] [PubMed]

58. Du, J.; Shen, J.; Wang, Y.; Pan, C.; Pang, W.; Diao, H.; Dong, W. Boar seminal plasma exosomes maintain sperm function by infiltrating into the sperm membrane. Oncotarget 2016, 7, 58832-58847. [CrossRef] [PubMed]

59. Robert, S.; Gilles, F.; Julie, G. Epididymosomes are involved in the acquisition of new sperm proteins during epididymal transit. Asian J. Androl. 2007, 9, 483-491.

60. Caballero, J.; Frenette, G.; Sullivan, R. Post testicular sperm maturational changes in the bull: Important role of the epididymosomes and prostasomes. Vet. Med. Int. 2010, 2010. [CrossRef] [PubMed]

61. Belleannée, C.; Calvo, É.; Caballero, J.; Sullivan, R. Epididymosomes convey different repertoires of microRNAs throughout the bovine epididymis1. Biol. Reprod. 2013, 89, 30. [CrossRef] [PubMed]

62. Frankel, A.I.; Chapman, J.C.; Cook, B. Testes are asymmetric in the testicular hemicastration response of the male rat. J. Endocrinol. 1989, 122, 485-488. [CrossRef] [PubMed]

63. Kosco, M.S.; Bolt, D.J.; Wheaton, J.E.; Loseth, K.J.; Crabo, B.G. Endocrine responses in relation to compensatory testicular growth after neonatal hemicastration in boars. Biol. Reprod. 1987, 36, 1177-1185. [CrossRef] [PubMed]

64. King, G.J.; Macpherson, J.W. A comparison of two methods for boar semen collection. J. Anim. Sci. 1973, 36, 563-565. [CrossRef] [PubMed]

65. Ma, J.; Wang, C.; Long, K.; Zhang, H.; Zhang, J.; Jin, L.; Tang, Q.; Jiang, A.; Wang, X.; Tian, S. Exosomal microRNAs in giant panda (Ailuropoda melanoleuca) breast milk: Potential maternal regulators for the development of newborn cubs. Sci. Rep. 2017, 7, 3507. [CrossRef] [PubMed]

66. Shen, H.M.; Dai, J.; Chia, S.E.; Lim, A.; Ong, C.N. Detection of apoptotic alterations in sperm in subfertile patients and their correlations with sperm quality. Hum. Reprod. 2002, 17, 1266-1273. [CrossRef] [PubMed]

67. Kummer, A.B.; Gaggini, T.S.; Bernardi, M.L.; Mcmanus, C.; Gonçales, E.M.; Wentz, I.; Bortolozzo, F.P. Multivariate analyses for determining the association of field porcine fertility with sperm motion traits analysed by computer-assisted semen analysis and with sperm morphology. Reprod. Domest. Anim. 2013, 48, 747-754. [CrossRef] [PubMed]

68. Broekhuijse, M.L.; Šoštarić, E.; Feitsma, H.; Gadella, B.M. Application of computer-assisted semen analysis to explain variations in pig fertility. J. Anim. Sci. 2012, 90, 779-789. [CrossRef] [PubMed]

69. Langmead, B. Aligning short sequencing reads with bowtie. Curr. Protoc. Bioinform. 2010. [CrossRef]

70. Livak, K.J.; Schmittgen, T.D. Analysis of relative gene expression data using real-time quantitative pcr and the $2^{-\Delta \Delta \text { ct }}$ method. Methods 2001, 25, 402-408. [CrossRef] [PubMed]

71. Gentleman, R.; Ihaka, R. R: A language and environment for statistical computing. Computing 2013, 14, 12-21.

72. Benjamini, Y.; Hochberg, Y. Controlling the false discovery rate: A practical and powerful approach to multiple testing. J. R. Stat. Soc. 1995, 57, 289-300.

(C) 2018 by the authors. Licensee MDPI, Basel, Switzerland. This article is an open access article distributed under the terms and conditions of the Creative Commons Attribution (CC BY) license (http://creativecommons.org/licenses/by/4.0/). 